\title{
Why are we still debating criteria for carotid artery stenosis?
}

\author{
Victor J. Del Brutto ${ }^{1}$, Heather L. Gornik ${ }^{2}$, Tatjana Rundek ${ }^{1}$ \\ ${ }^{1}$ Department of Neurology, Miller School of Medicine, University of Miami, Miami, FL, USA; ${ }^{2}$ Department of Cardiovascular Medicine, University \\ Hospitals Harrington Heart and Vascular Institute, Cleveland, OH, USA \\ Contributions: (I) Conception and design: All authors; (II) Administrative support: T Rundek; (III) Provision of study materials or patients: All authors; \\ (IV) Collection and assembly of data: All authors; (V) Data analysis and interpretation: All authors; (VI) Manuscript writing: All authors; (VII) Final \\ approval of manuscript: All authors. \\ Correspondence to: Tatjana Rundek, MD, PhD. Department of Neurology, Miller School of Medicine, University of Miami, 1120 NW $14^{\text {th }}$ Street, \\ Don Soffer Clinical Research Center, Suite 1348, Miami, FL 33136, USA. Email: trundek@med.miami.edu.
}

\begin{abstract}
The risk of new or recurrent stroke is high among patients with extracranial carotid artery stenosis and the benefit of carotid revascularization is associated to the degree of luminal stenosis. Catheterbased digital subtraction angiography (DSA) as the diagnostic gold-standard for carotid stenosis (CS) has been replaced by non-invasive techniques including duplex ultrasound, computed-tomography angiography, and magnetic resonance angiography (MRA). Duplex ultrasound is the primary noninvasive diagnostic tool for detecting, grading and monitoring of carotid artery stenosis due to its low cost, high resolution, and widespread availability. However, as discussed in this review, there is a wide range of practice patterns in use of ultrasound diagnostic criteria for carotid artery stenosis. To date, there is no internationally accepted standard for the gradation of CS. Discrepancies in ultrasound criteria may result in clinically relevant misclassification of disease severity leading to inappropriate referral, or lack of it, to revascularization procedures, and potential for consequential adverse outcome. The Society of Radiologists in Ultrasound (SRU), either as originally outlined or in a modified form, are the most common criteria applied. However, such criteria have received criticism for relying primarily on peak systolic velocities, a parameter that when used in isolation could be misleading. Recent proposals rely on a multiparametric approach in which the hemodynamic consequences of carotid narrowing beyond velocity augmentation are considered for an accurate stenosis classification. Consensus criteria would provide standardized parameters for the diagnosis of CS and considerably improve quality of care. Accrediting bodies around the world have called for consensus on unified criteria for diagnosis of CS. A healthy debate between professionals caring for patients with CS regarding optimal CS criteria still continues.
\end{abstract}

Keywords: Carotid artery stenosis; diagnostic criteria; ultrasound

Submitted Feb 03, 2020. Accepted for publication Apr 27, 2020.

doi: 10.21037/atm-20-1188a

View this article at: http://dx.doi.org/10.21037/atm-20-1188a

\section{Introduction}

Atherosclerosis affecting the cervical internal carotid artery (ICA) is an important cause of cerebral infarction, being responsible for $10 \%$ to $20 \%$ of cases of ischemic stroke $(1,2)$. A primary physical or metabolic injury to the endothelium may trigger an inflammatory response resulting in cellular proliferation and lipid deposition leading to the formation of atherosclerotic plaque (3). The bifurcation of the common carotid artery (CCA) is particularly prone to plaque formation due to the alterations of wall shear stress caused by the division of blood flow velocities (4). Carotid plaque may progress and protrude into the vessel lumen causing significant arterial narrowing and disruption of laminar flow (3). Finally, progressive arterial narrowing may lead to severe carotid stenosis (CS) or plaque rupture followed by thrombosis and embolism that may compromise cerebral circulation and result in stroke. 
The prevalence of asymptomatic extracranial CS in the general population is $4 \%$ to $8 \%$, increases with age and is more common in men than in women $(5,6)$. The main factor affecting the risk of stroke among patients with CS is the degree of luminal stenosis (7-9). The annual risk of stroke among patients with asymptomatic carotid disease with less than $60 \%$ stenosis is close to $1 \%$, but this risk increases to $3 \%$ to $4 \%$ for those with stenosis greater than $60 \%$ (9). The risk of stroke among patients who have had a previous episode of hemispheric transient ischemic attack, retinal ischemia, or ischemic stroke in the carotid artery territory (symptomatic CS) is much higher, up to $16 \%$ in the first year after an index event among medically treated patients (10), and similar to asymptomatic patients, it is closely related to the degree of stenosis $(9,11)$. Moreover, the value of carotid revascularization in patients with asymptomatic and symptomatic CS is predominantly dependent on the severity of stenosis (12-14). Two randomized trials showed a small but significant benefit of carotid endarterectomy (CEA) in patients with asymptomatic CS of $>60 \%(12,13)$. Likewise, pooled data from large randomized trials in symptomatic CS showed substantial benefit of CEA in patients with stenosis of $70 \%$ to $99 \%$, a modest benefit for those with $50 \%$ to $69 \%$ stenosis, and no benefit or harm for those with $<50 \%$ stenosis (14). It is therefore critically important to use accurate imaging techniques and diagnostic criteria for the detection and grading of severity of stenosis for the appropriate prognosis and therapeutic considerations in patients with CS. This review addresses the criteria for the diagnosis of CS with special emphasis in the advantages and challenges of carotid duplex ultrasound (CDUS) as a preferred screening and diagnostic tool for CS in clinical practice. After more than sixty years of the use of CDUS in clinical practice, setting the debate on appropriate diagnostic criteria for CS is still needed for the benefit of our patients, their caregivers, and society at large.

\section{Diagnosis of extracranial carotid artery stenosis}

The indications to refer symptomatic patients for the evaluation of CS include a transient ischemic attack, amaurosis fugax, or ischemic stroke (15). CS assessment is also commonly included as part of the diagnostic evaluation of non-specific non-hemispheric symptoms such as syncope, although it has been recognized as a low-yield practice $(16,17)$. Screening for CS in the general population, even among those with evidence of atherosclerosis in other vascular beds (i.e., coronary or peripheral artery disease), is neither indicated nor considered cost-effective (18-20). The rationale against widespread CS screening is based on the high-rate of false negative/positive results among the general population and the potential harm of unnecessary invasive procedures (18). Although more research is required in the field, some authors suggest that screening for CS among high-risk individuals would enable timely implementation of medical therapy to prevent stroke and cardiovascular events (21). Clinically, CS is usually suspected based on the presence of a carotid bruit on physical examination or Hollenhorst plaques on fundoscopy (22). The existence of a carotid bruit correlates poorly with the presence and degree of ICA stenosis $(23,24)$. Nevertheless, the presence of a carotid bruit continues to be a useful clinical sign to identify patients at high risk of cardiovascular events who would benefit from aggressive modification of vascular risks factors $(24,25)$.

Non-invasive tests utilized for the diagnosis of CS include high-resolution duplex ultrasound, time-of-flight and contrast-enhanced magnetic resonance angiography (MRA), and computed tomography angiography (CTA). All of them have demonstrated reasonable sensitivity and specificity when compared to the gold-standard of catheterbased digital subtraction angiography (DSA) (26) (Table 1). A meta-analysis of 41 studies including 2,541 patients (4,876 arteries), determined that contrast-enhanced MRA was more accurate than other non-invasive techniques to categorize $70-99 \%$ stenosis, yet data for $50-69 \%$ stenosis were less reliable (26). The incorporation of a contrast enhanced agent such as gadolinium to conventional MRA enables great distinction between the vessel and surrounding tissue leading to delineation of the vascular lumen independent of flow dynamics (27). In real-world practice, CDUS is often favored as a screening technique for being inexpensive, reliable, and readily available (28). It has been estimated that as many as $80 \%$ of patients in the U.S. undergo carotid revascularization after CDUS as the only preoperative diagnostic modality (29). While DSA remains the gold standard for assessing the severity of CS, it is usually reserved for selected situations or when an intervention, generally carotid artery stenting, is planned due to the risks related to the invasiveness of the procedure (30).

In CDUS, the degree of stenosis is graded by assessing the blood flow waveform at the site of greatest arterial narrowing. The procedure is inexpensive, has basically no risks, and represents minimal discomfort to the patient. The 


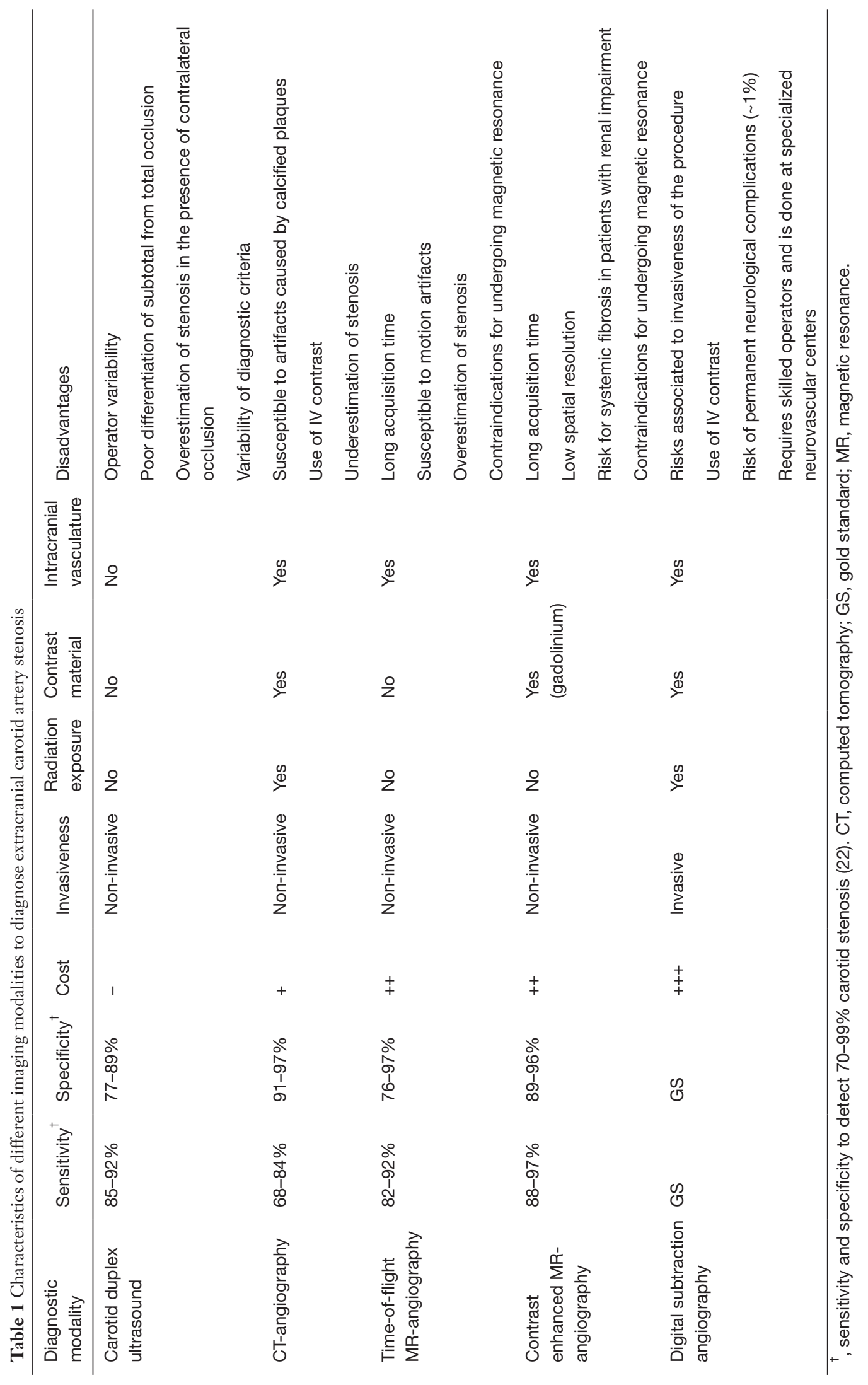


standard CDUS examination includes grayscale B-mode imaging, color Doppler imaging, and spectral Doppler velocity evaluation $(15,31,32)$ (Table 2). The recommended measurements on spectral Doppler evaluation include the peak-systolic velocity (PSV) and end-diastolic velocity (EDV), both at the distal CCA and ICA $(15,31)$. The highest ICA PSV in the site of stenosis together with plaque and lumen visualization on grayscale and Doppler images are the most practical parameters used to diagnose and grade CS $(29,33)$. Additional parameters include the ICA EDV, the ratio between the ICA PSV and distal CCA PSV (PSVs ratio), and the ratio between the ICA PSV and the CCA EDV, known as the St. Mary ratio $(34,35)$. These parameters are particularly useful when ICA PSV is not representative of the extent of stenosis, such as in the presence of tandem lesions, contralateral high-grade stenosis, elevated CCA velocities, hyperdynamic cardiac state, and low cardiac output $(29,36)$. In addition to velocity parameters, the presence of post-stenotic turbulence on color and spectral Doppler, as well as the morphology of the waveform distal to the area of most severe stenosis, can be useful for identification of high-risk carotid lesions. In cases of carotid near occlusion, velocity parameters may be increased or decreased, thus are not applicable or useful for diagnosis (29). Near occlusion diagnosis is made by demonstration of marked lumen narrowing on B-mode and color Doppler imaging as well as abnormal morphology of the spectral Doppler waveforms (37). Similarly, diagnosis of total carotid occlusion is suspected when there is extensive plaque visualized without detectable lumen on B-mode imaging and no flow on Doppler imaging (37). Diagnostic confirmation with either CTA, MRA or DSA are recommended in the latter two scenarios (29).

\section{Diagnostic criteria for extracranial carotid artery stenosis}

Seminal trials that demonstrated the benefit of CEA in patients with symptomatic CS utilized criteria based on DSA imaging to estimate the degree of ICA stenosis $(10,38,39)$. In the North American Symptomatic Carotid Endarterectomy Trial (NASCET) and the Veterans Affairs Cooperative Studies Program (10,39), the degree of luminal stenosis was calculated based on the ratio between the diameter at the point of greatest stenosis and the diameter of the artery at a normal distal segment. In the European Carotid Surgery Trial (ECST), the denominator utilized was an estimate of the original width of the artery at the site of maximal stenosis (38). Despite major discrepancies in the degree of stenosis between studies, subsequent comparison of the two methods showed that the relation between them was approximately linear and a simple equation is able to convert measurements from one method to the other $($ ECST\% stenosis $=0.6 \times$ NASCET\% stenosis $+40 \%$ ) $(40,41)$ (Figure 1). For example, a CS of $70 \%$ estimated by the NASCET criteria is equivalent to $82 \%$ stenosis by the ECST method $[0.6 \times 70+40=82]$. Both in CTA and MRA, post-processing techniques applying three-dimensional volume-rendering algorithms can produce angiographic images similar to those on DSA and enable stenosis measurements in accordance to NASCET or ECST criteria (42). However, the source of some of inconsistencies on CDUS diagnostic criteria mentioned below originate from applying different DSA protocols (NASCET $v s$. ECST) as the standard reference (43). Most organizations now recommend using the NASCET method when DSA is used to correlate CDUS findings $(29,36,43)$. Although, it is worth mentioning that the NASCET criteria may underestimate the degree of stenosis when there is decreased flow into the post-stenotic ICA due to collateral circulations or tandem lesions, thus resulting in an abnormally decreased diameter of the distal "normal" carotid artery segment.

Since the initial parameters known as the "Strandness Criteria" were published in 1987 (44), many different CDUS approaches to classify the severity of stenosis have been proposed (29,36,43,45-51) (Table 3). The Society of Radiologists in Ultrasound (SRU) consensus criteria are widely used and recommend PSV cutoff values of $>125 \mathrm{~cm} / \mathrm{s}$ and $>230 \mathrm{~cm} / \mathrm{s}$ to define stenosis $\geq 50 \%$ and $\geq 70 \%$, respectively (29). Additional criteria include PSVs ratio $>2.0$ and $\mathrm{EDV}>40$ for $\geq 50 \%$ stenosis, and PSVs ratio $>4.0$ and $\mathrm{EDV}>100 \mathrm{~cm} / \mathrm{s}$ for $\geq 70 \%$ stenosis (29). Two successive validation studies reported that $\mathrm{PSV}>230 \mathrm{~cm} / \mathrm{s}$ had a sensitivity of 0.95 and 0.99 , and specificity of 0.84 and 0.86 for detecting $\geq 70 \%$ stenosis $(52,53)$. One of those studies, which used CTA as the reference standard, also evaluated the accuracy of PSV $125-230 \mathrm{~cm} / \mathrm{s}$ for detecting 50-69\% stenosis and reported a sensitivity of 0.93 and specificity of 0.68 , which could be significantly improved by using a PSV of $140-230 \mathrm{~cm} / \mathrm{s}$ resulting in a sensitivity of 0.94 and specificity of 0.92 (52). The Vascular Society of Great Britain and Ireland adopted the PSV cutoff values proposed by the SRU, with an additional cutoff of $>400 \mathrm{~cm} / \mathrm{s}$ to define $\geq 90 \%$ stenosis but less than near occlusion (43). The British consensus also encouraged the use of the St. Mary 
Table 2 Summary of the Society for Vascular Ultrasound exam protocol performance guidelines for extracranial cerebrovascular duplex ultrasound (32)

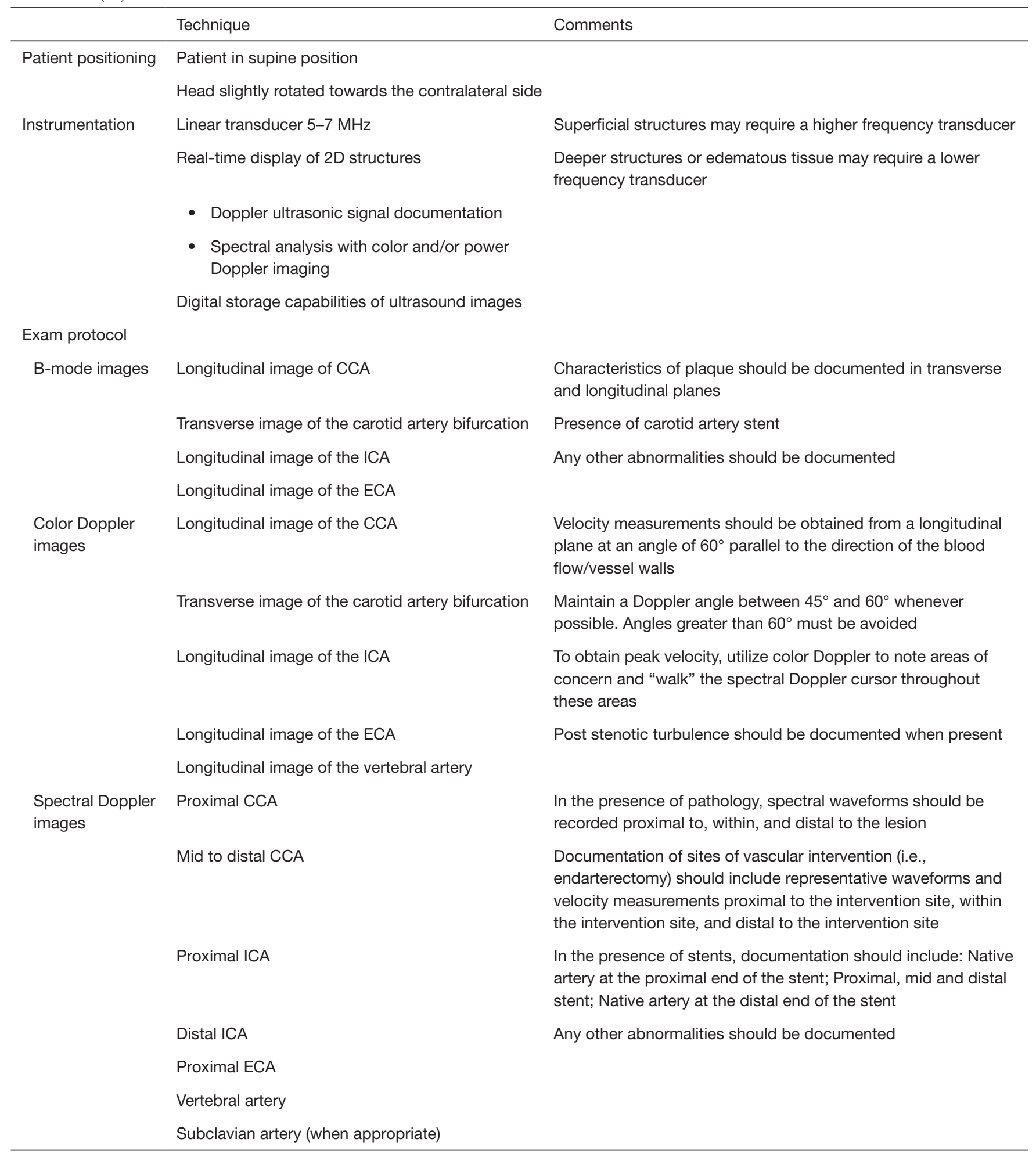

CCA, common carotid artery; ECA, external carotid artery; ICA, internal carotid artery. 


\begin{tabular}{|c|c|}
\hline \\
\hline Direct comparison of the degree of ICA stenosis used in \\
\hline
\end{tabular}

Figure 1 Diagram of the NASCET and ECST methodology for internal carotid artery stenosis measurement (41).

ratio as a robust index able to grade the degree of stenosis in deciles $(43,54)$. For example, a St Mary ratio of 11 indicates $60 \%$ stenosis with a sensitivity of 0.91 and specificity 0.94 , and a ratio of 14 indicates $70 \%$ stenosis with a sensitivity of 0.93 and specificity of 0.93 (54). Caution should be taken when using the St. Mary ratio in situations in which the CCA EDV is bilaterally decreased, such as in retrograde flow due to aortic insufficiency (55) or reduced vessel wall compliance (43).

Other CDUS criteria differ significantly from the AngloAmerican recommendations. Recommendations from the German DEGUM (Deutsche Gesellschaft für Ultraschall in der Medizin) include PSV cutoffs values of $>200 \mathrm{~cm} / \mathrm{s}$ and $>300 \mathrm{~cm} / \mathrm{s}$ (44), while the Swedish EQUALIS (External Quality Assurance in Laboratory Medicine in Sweden) recommend PSV cutoff values of $>230 \mathrm{~cm} / \mathrm{s}$ and $>320 \mathrm{~cm} / \mathrm{s}$ for stenosis of $\geq 50 \%$ and $\geq 70 \%$, respectively (46). More recently, the Neurosonology Research Group of the World Federation of Neurology recommended a multiparametric approach using both morphological and hemodynamic parameters to define primary and additional criteria in order to overcome common diagnostic errors met when PSV are used in isolation (36). The relative value of such parameters depends on the severity of stenosis. For low-degree stenosis (0-50\%), morphological characteristics on B-mode imaging including the thickness and length the plaque, as well as the reduction of diameter in percent, are more meaningful than velocity measurements (36). In moderate stenosis (i.e., 50 59\%, 60-69\%), morphological criteria are combined with increase in PSV (usually $125-230 \mathrm{~cm} / \mathrm{s}$ ) and no collateral flow present. For hemodynamically severe stenosis $(\geq 70 \%)$, increase in velocity $(>230 \mathrm{~cm} / \mathrm{s})$ is accompanied of signs of collateral flow by transcranial Doppler demonstrated by retrograde flow on the ophthalmic artery, cross flow on the anterior cerebral artery, or P1 collateral flow through the posterior communicating artery (36). In the latter, reduced velocity in the post-stenotic segments (i.e., $<30 \mathrm{~cm} / \mathrm{s}$ PSV) and dampened and delayed Doppler waveform morphology, indicates very severe stenosis (>90\%) (36).

There is substantial variability from laboratory to laboratory in the CDUS thresholds and derived indices applied to diagnose and grade CS (56-60). Even among accredited vascular testing centers, the diagnostic thresholds for CS severity vary considerably (60). Among 338 accredited centers in the U.S., the PSV threshold for moderate stenosis (50\% to 69\%) ranged from 110 to $245 \mathrm{~cm} / \mathrm{s}$, and the threshold for severe stenosis (>70\%) ranged from 175 to $340 \mathrm{~cm} / \mathrm{s}$. When applied this wide range of thresholds for moderate stenosis in a populationbased sample of individuals aged $>65$ years, twice as many cases would be assigned the diagnosis of moderate stenosis when the $5^{\text {th }}$ percentile threshold was compared to the $95^{\text {th }}$ percentile. Similarly, in a large cohort of asymptomatic patients who underwent carotid revascularization, one in ten cases would warrant the diagnosis of severe stenosis, thus considered for surgery, in the $5^{\text {th }}$ percentile threshold, but not in the $95^{\text {th }}$ percentile threshold (60). These estimations expose the high clinical impact CDUS diagnostic criteria variations across testing centers may have. 
Table 3 Consensus criteria on carotid ultrasound diagnostic criteria for $>50 \%$ and $>70 \%$ carotid stenosis

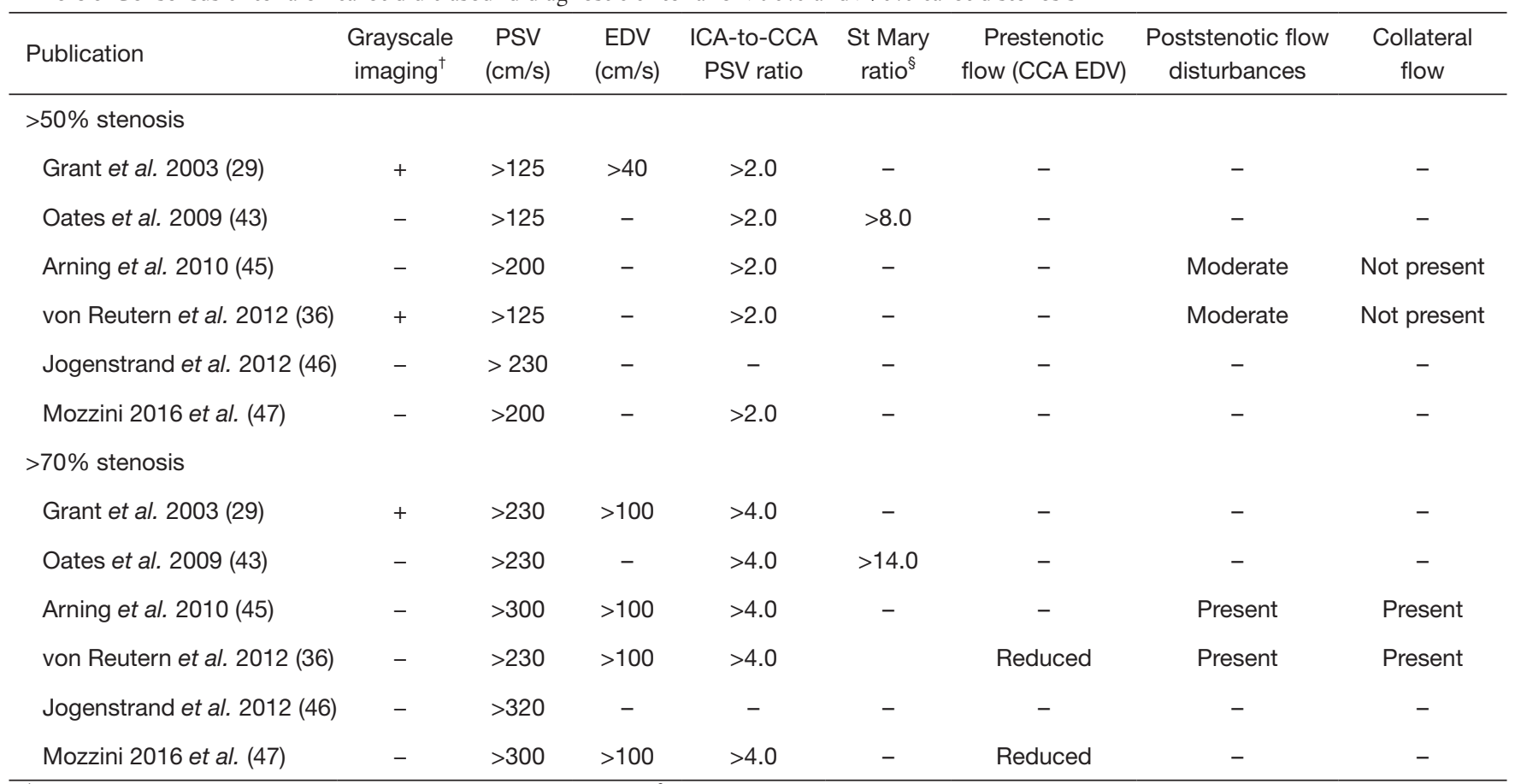

${ }^{\dagger}$, criteria mention features on grayscale B-mode imaging; ${ }^{\S}$, St Mary ratio = ICA PSV/CCA EDV. CCA, common carotid artery; EDV, end diastolic velocity; ICA, internal carotid artery; PSV, peak systolic velocity.

\section{Pitfalls and challenges in the use of carotid ultrasound for the diagnosis of extracranial carotid artery stenosis}

The main source of variation in CDUS criteria arises from the exponential relation between the angiographic degree of stenosis (considered the gold standard) and the PSV on spectral Doppler originally described by Spencer and Reid $(61,62)$. The steep graph leads to a significant change in velocity despite minimal changes in the angiographic degree of stenosis, particularly in the range of highest clinical relevance $(60 \%$ to $90 \%)$. In addition, the "Spencer Reid curve" may result in reduced velocities in situations of near occlusion which may be misclassified as lower degrees of stenosis (62). A systematic review of 22 data sets found a wide variability between CDUS velocities and percent of stenosis on angiography among published data, which in turn have resulted in the inconsistencies of the different diagnostic thresholds proposed in the literature (59). Moreover, both modalities are not expected to entirely correlate as angiography measures the reduction in the vessel diameter, while PSV as measured by Doppler ultrasound is altered by the reduction in the lumen area, which is mainly determined by the morphology of the plaque (63). It is therefore that PSV alone is considered insufficient for accurate estimation of the degree of CS (36). Factors relevant to angiographic measurements that may contribute to inconsistencies between CDUS and angiographic degree of stenosis include the presence of noncircular stenoses as well as the pulsatile changes in the lumen diameter that occur between systole and diastole (59). Indeed, as stated in the title of a summary analysis of previously published angiographic and Doppler ultrasound comparative studies, "correlation is futile" (59).

Conditions inherent to the patient may also influence CDUS examinations. Certain variability within patients can be attributed to factors affecting brain physiology such as carbon dioxide exposure, caffeine, lactate, nicotine, and degree of regional brain activation (64-67). Some vessel characteristics such as extensive plaque calcification, increased tortuosity, and tandem lesions, may result in difficult interpretation of CDUS results (29). Overestimation or underestimation of the degree of stenosis may occur when flow velocities are affected by hemodynamic factors such as low cardiac output, irregular heart rhythm, and hyperdynamic cardiac state (43). The 
presence of collateral flow, either through the Circle of Willis or the ophthalmic artery, may decrease the poststenotic pressure and, consequently, the intra-stenotic velocity $(68,69)$. Conversely, the presence of contralateral severe CS or occlusion may falsely elevate CDUS velocities (70,71). Ultimately, the presence of a carotid stent results in higher PSVs and lower EDV and PSV ratio, and therefore it is recommended to be considered for the interpretation of CDUS (60).

Technical considerations that may affect the accuracy of measurements, hence the reliability of CDUS investigations, include completeness of the examination protocol, the angle of insonation, equipment variability, and methods of reporting, which vary significantly from laboratory to laboratory $(72,73)$. The angle of insonation is required to convert the Doppler frequencies into velocities, thus is a critical determinant of the Doppler velocity measurement. It has been estimated that small shifts in angle of insonation result in major discrepancies between studies $(74,75)$. Is important to highlight that an appropriate angle estimation is particularly challenging in situations of turbulent flow or tortuous vessels. Most organizations emphasize that measurements should be done at a fixed angle and recommend an angle of 60 degrees or lower $(15,29,31,43)$, nonetheless, the optimal angle of insonation continues to be a matter of debate (47).

Several professional societies and accrediting bodies including the Intersocietal Accreditation Commission (IAC), the American Institute of Ultrasound in Medicine (AIUM), Society for Vascular Ultrasound (SVU), and the American College of Radiology (ACR) have been tasked to standardize the examination protocols and methods for reporting for CS (Table 2) $(15,31,32)$. These organizations suggest that stenoses above $50 \%$ should be graded within a range (i.e., $50-69 \%$ or $70 \%$ to near occlusion) to provide adequate information for clinical decision making. They also emphasize that each laboratory must apply uniform diagnostic criteria either derived from the literature or from internal validation based on correlation with other imaging modalities or pathological samples $(15,31)$. Accreditation status of a vascular laboratory is an important feature associated with enhanced diagnostic accuracy and reliability (76). However, a recent study reported that only $22 \%$ of outpatient cerebrovascular testing facilities in the U.S. which performed testing for Medicare patients were IAC-accredited, and accreditation status varied widely by geographical region (77). Among IAC-accredited testing facilities, there is wide variability of carotid diagnostic criteria employed by individual laboratories, as well as support for efforts to standardize diagnostic criteria across the board (78). In response to these data, IAC has undertaken an initiative to standardize diagnostic criteria across its accredited laboratories, the first phase of which, a research study to validate the SRU Consensus criteria, compared to DSA, and to propose modification of SRU Consensus parameters for optimized accuracy is due to be released in 2020.

\section{Conclusions}

For many reasons, CDUS remains the primary modality for initial diagnosis and monitoring of CS, and plays a central role in the management of patient care and clinical decision making. Although debate continues regarding the optimal diagnostic criteria for diagnosis of carotid artery stenosis, we are closer to accomplishing our goal of standardization of CS criteria worldwide and improving quality of care for these patients.

\section{Acknowledgments}

Funding: None.

\section{Footnote}

Provenance and Peer Review: This article was commissioned by the Guest Editor (Dr. Kosmas I. Paraskevas) for the series "Carotid Artery Stenosis and Stroke: Prevention and Treatment Part I" published in Annals of Translational Medicine. The article was sent for external peer review organized by the Guest Editor and the editorial office.

Conflicts of Interest: All authors have completed the ICMJE uniform disclosure form (available at http://dx.doi. org/10.21037/atm-20-1188a). The series "Carotid Artery Stenosis and Stroke: Prevention and Treatment Part I" was commissioned by the editorial office without any funding or sponsorship. HLG reports other from Flexlife Health, outside the submitted work; and is a non-compensated member of the Board of Directors of IAC Vascular Testing. TR reports grants from National Institute of Health, outside the submitted work. The other author has no other conflicts of interest to declare.

Ethical Statement: The authors are accountable for all aspects of the work in ensuring that questions related 
to the accuracy or integrity of any part of the work are appropriately investigated and resolved.

Open Access Statement: This is an Open Access article distributed in accordance with the Creative Commons Attribution-NonCommercial-NoDerivs 4.0 International License (CC BY-NC-ND 4.0), which permits the noncommercial replication and distribution of the article with the strict proviso that no changes or edits are made and the original work is properly cited (including links to both the formal publication through the relevant DOI and the license). See: https://creativecommons.org/licenses/by-nc-nd/4.0/.

\section{References}

1. Fisher M. Occlusion of the internal carotid artery. AMA Arch Neurol Psychiatry 1951;65:346-77.

2. Sacco RL, Ellenberg JH, Mohr JP, et al. Infarcts of undetermined cause: the NINCDS Stroke Data Bank. Ann Neurol 1989;25:382-90.

3. Hall HA, Bassiouny HS. Pathophysiology of carotid atherosclerosis. In: Nicolaides A, Beach KW, Kyriacou E, et al. editors. Ultrasound Carotid Bifurc Atheroscler. New York: Springer; 2012:27-39.

4. Dhawan SS, Avati Nanjundappa RP, Branch JR, et al. Shear stress and plaque development. Expert Rev Cardiovasc Ther 2010;8:545-56.

5. Mineva PP, Manchev IC, Hadjiev DI. Prevalence and outcome of asymptomatic carotid stenosis: a populationbased ultrasonographic study. Eur J Neurol 2002;9:383-8.

6. Goessens BM, Visseren FL, Kappelle LJ, et al. Asymptomatic carotid artery stenosis and the risk of new vascular events in patients with manifest arterial disease: the SMART study. Stroke 2007;38:1470-5.

7. Satiani B, Porter RM Jr, Biggers KM, et al. Natural history of non-operated, significant carotid stenosis. Ann Vasc Surg 1988;2:271-8.

8. Autret A, Pourcelot L, Saudeau D, et al. Stroke risk in patients with carotid stenosis. Lancet 1987;1:888-90.

9. Inzitari D, Eliasziw M, Gates $\mathrm{P}$, et al. The causes and risk of stroke in patients with asymptomatic internal-carotidartery stenosis. North American Symptomatic Carotid Endarterectomy Trial Collaborators. N Engl J Med 2000;342:1693-700.

10. North American Symptomatic Carotid Endarterectomy Trial Collaborators, Barnett HJM, Taylor DW, et al. Beneficial effect of carotid endarterectomy in symptomatic patients with high-grade carotid stenosis. N Engl J Med
1991;325:445-53.

11. Dennis MS, Bamford JM, Sandercock PA, et al. A comparison of risk factors and prognosis for transient ischemic attacks and minor ischemic strokes. The Oxfordshire Community Stroke Project. Stroke 1989;20:1494-9.

12. Endarterectomy for asymptomatic carotid artery stenosis. Executive Committee for the Asymptomatic Carotid Atherosclerosis Study. JAMA 1995;273:1421-8.

13. Halliday A, Harrison M, Hayter E, et al; Asymptomatic Carotid Surgery Trial (ACST) Collaborative Group 10-year stroke prevention after successful carotid endarterectomy for asymptomatic stenosis (ACST-1): a multicentre randomised trial. Lancet 2010;376:1074-84.

14. Rothwell PM, Eliasziw M, Gutnikov SA, et al. Analysis of pooled data from the randomised controlled trials of endarterectomy for symptomatic carotid stenosis. Lancet 2003;361:107-16.

15. AIUM Practice Parameter for the Performance of a Thyroid and Parathyroid Ultrasound Examination. J Ultrasound Med 2016;35:1-11.

16. Dittmar PC, Feldman LS. Carotid artery ultrasound for syncope. J Hosp Med 2016;11:117-9.

17. Langer-Gould AM, Anderson WE, Armstrong MJ, et al. The American Academy of Neurology's top five choosing wisely recommendations. Neurology 2013;81:1004-11.

18. LeFevre ML; U.S. Preventive Services Task Force. Screening for asymptomatic carotid artery stenosis: U.S. Preventive Services Task Force recommendation statement. Ann Intern Med 2014;161:356-62.

19. Brott TG, Halperin JL, Abbara S, et al. 2011 ASA/ACCF/ AHA/AANN/AANS/ACR/ASNR/CNS/SAIP/SCAI/SIR/ SNIS/SVM/SVS guideline on the management of patients with extracranial carotid and vertebral artery disease: executive summary. A report of the American College of Cardiology Foundation/American Heart Association Task Force on Practice Guidelines, and the American Stroke Association, American Association of Neuroscience Nurses, American Association of Neurological Surgeons, American College of Radiology, American Society of Neuroradiology, Congress of Neurological Surgeons, Society of Atherosclerosis Imaging and Prevention, Society for Cardiovascular Angiography and Interventions, Society of Interventional Radiology, Society of NeuroInterventional Surgery, Society for Vascular Medicine, and Society for Vascular Surgery. Circulation 2011;124:489-532.

20. Lee TT, Solomon NA, Heidenreich PA, et al. Cost- 
effectiveness of screening for carotid stenosis in asymptomatic persons. Ann Intern Med 1997;126:337-46.

21. Paraskevas KI, Eckstein HH, Mikhailidis DP, et al. Rationale for screening selected patients for asymptomatic carotid artery stenosis. Curr Med Res Opin 2020;36:361-5.

22. Bakri SJ, Luqman A, Pathik B, et al. Is carotid ultrasound necessary in the clinical evaluation of the asymptomatic Hollenhorst plaque? (An American Ophthalmological Society thesis). Trans Am Ophthalmol Soc 2013;111:17-23.

23. Ratchford EV, Jin Z, Di Tullio MR, et al. Carotid bruit for detection of hemodynamically significant carotid stenosis: The Northern Manhattan Study. Neurol Res 2009;31:748-52.

24. Paraskevas KI, Hamilton G, Mikhailidis DP. Clinical significance of carotid bruits: an innocent finding or a useful warning sign? Neurol Res 2008;30:523-30.

25. Pickett CA, Jackson JL, Hemann BA, et al. Carotid bruits as a prognostic indicator of cardiovascular death and myocardial infarction: a meta-analysis. Lancet 2008;371:1587-94.

26. Wardlaw JM, Chappell FM, Best JJ, et al. Non-invasive imaging compared with intra-arterial angiography in the diagnosis of symptomatic carotid stenosis: a meta-analysis. Lancet 2006;367:1503-12.

27. Serfaty JM, Chirossel P, Chevallier JM, et al. Accuracy of three-dimensional gadolinium-enhanced MR angiography in the assessment of extracranial carotid artery disease. AJR Am J Roentgenol 2000;175:455-63.

28. Lanzino G, Tallarita T, Rabinstein AA. Internal carotid artery stenosis: natural history and management. Semin Neurol 2010;30:518-27.

29. Grant EG, Benson CB, Moneta GL, et al. Carotid artery stenosis: grayscale and Doppler ultrasound diagnosis-Society of Radiologists in Ultrasound consensus conference. Ultrasound Q 2003;19:190-8.

30. Chilcote WA, Modic MT, Pavlicek WA, et al. Digital subtraction angiography of the carotid arteries: a comparative study in 100 patients. Radiology 1981;139:287-95.

31. Intersocietal Accreditation Commission (IAC). IAC Standards and Guidelines for Vascular Testing Accreditation. July 2019. Available online: https://www.intersocietal.org/vascular/standards/ IACVascular'TestingStandards2019.pdf. Accessed January 28, 2020.

32. Society for Vascular Ultrasound (SVU). Vascular Technology Professional Performance Guidelines: Extracranial Cerebrovascular Duplex Ultrasound. January
2019. Available online: https://higherlogicdownload. s3.amazonaws.com/SVUNET/c9a8d83b-2044-4a4eb3eccd4b2f542939/UploadedImages/PPG_Docs/1_ Extracranial_Cerebrovascular_Duplex_Ultrasound_ Evaluation_Updated_2019_.pdf. Accessed January 28, 2020.

33. Grant EG, Duerinckx AJ, El Saden SM, et al. Ability to use duplex US to quantify internal carotid arterial stenoses: fact or fiction? Radiology 2000;214:247-52.

34. Hunink MG, Polak JF, Barlan MM, et al. Detection and quantification of carotid artery stenosis: efficacy of various Doppler velocity parameters. AJR Am J Roentgenol 1993;160:619-25.

35. Knox RA, Breslau PJ, Strandness DE Jr. A simple parameter for accurate detection of severe carotid disease. Br J Surg 1982;69:230-3.

36. von Reutern GM, Goertler MW, Bornstein NM, et al. Grading carotid stenosis using ultrasonic methods. Stroke 2012;43:916-21.

37. El-Saden SM, Grant EG, Hathout GM, et al. Imaging of the internal carotid artery: the dilemma of total versus near total occlusion. Radiology 2001;221:301-8.

38. Randomised trial of endarterectomy for recently symptomatic carotid stenosis: final results of the MRC European Carotid Surgery Trial (ECST). Lancet 1998;351:1379-87.

39. Mayberg MR, Wilson SE, Yatsu F, et al. Carotid endarterectomy and prevention of cerebral ischemia in symptomatic carotid stenosis. Veterans Affairs Cooperative Studies Program 309 Trialist Group. JAMA 1991;266:3289-94.

40. Rothwell PM, Gibson RJ, Slattery J, et al. Equivalence of measurements of carotid stenosis. A comparison of three methods on 1001 angiograms. European Carotid Surgery Trialists' Collaborative Group. Stroke 1994;25:2435-9.

41. Donnan GA, Davis SM, Chambers BR, et al. Surgery for prevention of stroke. Lancet 1998;351:1372-3.

42. U-King-Im JM, Young V, Gillard JH. Carotid-artery imaging in the diagnosis and management of patients at risk of stroke. Lancet Neurol 2009;8:569-80.

43. Oates CP, Naylor AR, Hartshorne T, et al. Joint recommendations for reporting carotid ultrasound investigations in the United Kingdom. Eur J Vasc Endovasc Surg 2009;37:251-61.

44. Taylor DC, Strandness DE Jr. Carotid artery duplex scanning. J Clin Ultrasound 1987;15:635-44.

45. Arning C, Widder B, von Reutern GM, et al. Revision of DEGUM ultrasound criteria for grading internal carotid artery stenoses and transfer to NASCET measurement. 
Ultraschall Med 2010;31:251-7.

46. Jogestrand T, Fredén-Lindqvist J, Lindqvist M, et al. Equalis criteria for carotid artery diagnostics-under continuous revision. Lakartidningen 2012;109:702-3.

47. Mozzini C, Roscia G, Casadei A, et al. Searching the perfect ultrasonic classification in assessing carotid artery stenosis: comparison and remarks upon the existing ultrasound criteria. J Ultrasound 2016;19:83-90.

48. Gorican K, Chochola M, Kocik M, et al. Diagnostic criteria for the determination of clinically significant internal carotid artery stenosis using duplex ultrasound. Biomed Pap Med Fac Univ Palacky Olomouc Czech Repub 2020;164:255-60.

49. Rodriguez G, Arnaldi D, Campus C, et al. Correlation between Doppler velocities and duplex ultrasound carotid cross-sectional percent stenosis. Acad Radiol 2011;18:1485-91

50. Shaalan WE, Wahlgren CM, Desai T, et al. Reappraisal of velocity criteria for carotid bulb/internal carotid artery stenosis utilizing high-resolution B-mode ultrasound validated with computed tomography angiography. J Vasc Surg 2008;48:104-12

51. Jahromi AS, Cinà CS, Liu Y, et al. Sensitivity and specificity of color duplex ultrasound measurement in the estimation of internal carotid artery stenosis: a systematic review and meta-analysis. J Vasc Surg 2005;41:962-72.

52. AbuRahma AF, Srivastava M, Stone PA, et al. Critical appraisal of the Carotid Duplex Consensus criteria in the diagnosis of carotid artery stenosis. J Vasc Surg 2011;53:53-9.

53. Braun RM, Bertino RE, Milbrandt J, et al. Ultrasound imaging of carotid artery stenosis: application of the Society of Radiologists in Ultrasoun Consensus Criteria to a Single Institution Clinical Practice. Ultrasound Q 2008;24:161-6.

54. Dhanjil S, Jameel M, Nicolaides A, et al. Ratio of peak systolic velocity of internal carotid to end diastolic velocity of common carotid: new duplex criteria for grading internal carotid stenosis. J Vasc Technol 1997;21:237.e40.

55. Kallman CE, Gosink BB, Gardner DJ. Carotid duplex sonography: bisferious pulse contour in patients with aortic valvular disease. AJR Am J Roentgenol 1991;157:403-7.

56. Arous EJ, Simons JP, Flahive JM, et al. National variation in preoperative imaging, carotid duplex ultrasound criteria, and threshold for surgery for asymptomatic carotid artery stenosis. J Vasc Surg 2015;62:937-44.

57. Walker J, Naylor AR. Ultrasound based measurement of 'carotid stenosis $>70 \%$ ': an audit of UK practice. Eur J
Vasc Endovasc Surg 2006;31:487-90.

58. McKenna MA, Bonfield MC, Robinson T. Levels of agreement in the measurements of carotid artery ultrasound across a regional vascular network. Ultrasound 2018;26:101-9.

59. Beach KW, Leotta DF, Zierler RE. Carotid Doppler velocity measurements and anatomic stenosis: correlation is futile. Vasc Endovascular Surg 2012;46:466-74.

60. Columbo JA, Zwolak RM, Arous EJ, et al. Variation in Ultrasound Diagnostic Thresholds for Carotid Stenosis in the United States. Circulation 2020;141:946-53.

61. Jogestrand T, Fredén-Lindqvist J, Lindqvist $M$, et al. Discrepancies in recommended criteria for grading of carotid stenosis with ultrasound. Clin Physiol Funct Imaging 2016;36:326-9.

62. Spencer MP, Reid JM. Quantitation of carotid stenosis with continuous-wave (C-W) Doppler ultrasound. Stroke 1979;10:326-30.

63. Zwiebel WJ, Austin CW, Sackett JF, et al. Correlation of high-resolution, B-mode and continuous-wave Doppler sonography with arteriography in the diagnosis of carotid stenosis. Radiology 1983;149:523-32.

64. Breslau PJ, Knox R, Fell G, et al. Effect of carbon dioxide on flow patterns in normal extracranial arteries. J Surg Res 1982;32:97-103.

65. Cameron OG, Modell JG, Hariharan M. Caffeine and human cerebral blood flow: a positron emission tomography study. Life Sci 1990;47:1141-6.

66. Mintun MA, Vlassenko AG, Rundle MM, et al. Increased lactate/pyruvate ratio augments blood flow in physiologically activated human brain. Proc Natl Acad Sci U S A 2004;101:659-64.

67. Boyajian RA, Otis SM. Acute effects of smoking on human cerebral blood flow: a transcranial Doppler ultrasonography study. J Neuroimaging 2000;10:204-8.

68. de Nie AJ, Blankensteijn JD, Visser GH, et al. Cerebral blood flow in relation to contralateral carotid disease, an MRA and TCD study. Eur J Vasc Endovasc Surg 2001;21:220-6.

69. Fujioka S, Karashima K, Nakagawa H, et al. Classification of ophthalmic artery flow in patients with occlusive carotid artery disease. Jpn J Ophthalmol 2006;50:224-8.

70. Henderson RD, Steinman DA, Eliasziw M, et al. Effect of contralateral carotid artery stenosis on carotid ultrasound velocity measurements. Stroke 2000;31:2636-40.

71. Grajo JR, Barr RG. Duplex Doppler sonography of the carotid artery: velocity measurements in an artery with contralateral stenosis. Ultrasound Q 2007;23:199-202. 
72. Kuntz KM, Polak JF, Whittemore AD, et al. Duplex ultrasound criteria for the identification of carotid stenosis should be laboratory specific. Stroke 1997;28:597-602.

73. Alexandrov AV, Vital D, Brodie DS, et al. Grading carotid stenosis with ultrasound. An interlaboratory comparison. Stroke 1997;28:1208-10.

74. Tola M, Yurdakul M. Effect of Doppler angle in diagnosis of internal carotid artery stenosis. J Ultrasound Med 2006;25:1187-92.

75. Beach KW, Bergelin RO, Leotta DF, et al. Standardized ultrasound evaluation of carotid stenosis for clinical trials: University of Washington Ultrasound Reading Center. Cardiovasc Ultrasound 2010;8:39.

76. Brown OW, Bendick PJ, Bove PG, et al. Reliability of

Cite this article as: Del Brutto VJ, Gornik HL, Rundek T. Why are we still debating criteria for carotid artery stenosis? Ann Transl Med 2020;8(19):1270. doi: 10.21037/atm-20-1188a extracranial carotid artery duplex ultrasound scanning: value of vascular laboratory accreditation. J Vasc Surg 2004;39:366-71.

77. Brown SC, Wang K, Dong C, et al. Intersocietal Accreditation Commission Accreditation Status of Outpatient Cerebrovascular Testing Facilities Among Medicare Beneficiaries: The VALUE Study. J Ultrasound Med 2016;35:1957-65.

78. Intersocietal Accreditation Commission Vascular Testing. IAC vascular testing white paper on carotid stenosis interpretation criteria. January 2014. Available online: www.intersocietal.org/vascular/main/links_references.htm. Accessed January 28, 2020. 